\title{
La importancia del filosofar en español para Juan David García Bacca: literatura y transustanciación.
}

\section{The importance of philosophize in spanish for Juan David García Bacca: Literature and transubstantiation}

\author{
XAVIER GIMENO MONFORT \\ Universidad de Valencia
}

Recibido: 20/03/15 Aceptado: $15 / 04 / 15$

\begin{abstract}
RESUMEN
El presente artículo pretende dar cuenta del origen y cambio radical de paradigma filosófico sufrido por el filósofo de origen Navarro Juan David García Bacca. En especial, trataremos de analizar cómo y por qué razón, el filósofo español pasa de desestimar la posibilidad de una forma propia del filosofar español desde una perspectiva ontológica, hasta tratar la poesía y la literatura como las formas idiosincráticas del hacer filosofía en español. Esta forma característicamente española de hacer filosofía en español será, pues, determinante para la comprensión del abandono de la etapa existencialista garcibaccquiana, y su renovado interés por la obra del poeta Antonio Machado, y su filosofar por y para el pueblo.
\end{abstract}

PALABRAS CLAVE

ONTOLOGÍA, GARCÍA BACCA, FILOSOFÍA, ESPAÑOL

\section{ABSTRACT}

This paper pursues to explain the origin and radical philosophical paradigm shift undergone by the philosopher from Navarre Juan David Garcia Bacca. Specifically, we will try to analyze

(C) Contrastes. Revista Internacional de Filosofia, vol. XXI-N²2 (2016), pp. 91-108. ISSN: 1136-4076 Departamento de Filosofía, Universidad de Málaga, Facultad de Filosofía y Letras Campus de Teatinos, E-29071 Málaga (España) 
how and why the Spanish philosopher moves from dismissing the possibility of a particular form of Spanish philosophizing from an ontological perspective, to treating poetry and literature as idiosyncratic ways of doing philosophy in Spanish. This typically Spanish way of doing philosophy in Spanish will be, therefore, crucial to understand the abandonment of the Garcibaccquian existentialist stage, and his renewed interest in the work of the poet Antonio Machado and his philosophizing by and for the people

KEYWORDS

ONTOLOGY, GARCÍA BACCA, PHILOSOPHY, SPANISH

\section{INTRODUCCIÓN}

LA PRINCIPAL INTENCIÓN DEL PRESENTE ARTículo es la de atender y exponer la importancia de la literatura española en la gestación y desarrollo de la propuesta metafísica garcibaccquiana durante los años 40 y 50 del pasado siglo. Hemos tratado de evitar las referencias a otros autores tales como Heidegger, Ortega y Whitehead que, si bien fueron determinantes en el desarrollo de la propuesta metafísica garcibaccquiana de este período, pensamos que en García Bacca existe un núcleo argumentativo original e independiente del peso de estos autores que debe ser atendido y expuesto. De especial y destacada importancia es, sin duda alguna, la importancia que García Bacca otorga a la literatura en español porque, tal y como se demuestra en el presente artículo, García Bacca cree que la idiosincrasia filosófica española se desarrolla originariamente a través de la literatura y la poesía.

En el presente artículo intentaremos, pues, presentar algunos aspectos cruciales que conforman el proyecto transustanciador-dialéctico garcibaccquiano. Para ello, centraremos nuestra atención en el problema de la literatura y sus posibilidades fenomenológicas.

La comparativa entre textos es, como podremos comprobar, una buena manera de evidenciar el poder contradictorio garcibaccquiano. Poder contradictorio que, lejos de constituir un problema, pone de manifiesto la facticidad misma de la transustanciación garcibaccquiana.

Empecemos, pues, por el principio.

\section{LA IMPORTANCIA DE LA LITERATURA COMO FILOSOFAR ESPAÑOL}

Antes de 1944-45, no existen referencias bibliográficas del propio filósofo español, en las que se muestre un interés filosófico-fenomenológico por la literatura y la poesía. Es más, el tono de la exposición y temáticas escogidas por García Bacca durante los años anteriores a 1944 se alejan mucho de la 
literatura y la poesía; incluso adopta una postura inicial contraria y crítica con las posibilidades filosóficas de la literatura y la poesía.

Empecemos, pues, por atender a la negativa inicial que García Bacca adopta respecto a la literatura como expresión filosófica. Para ello, nos centramos en una primera opinión adversa y contraria a las posibilidades mismas de la literatura expresada por el propio García Bacca en un artículo de 1944 titulado «El problema filosófico de la fenomenología literaria». ${ }^{1}$

El artículo se centra en una discusión sobre las palabras de Alfonso Reyes sobre un artículo publicado en el mismo número de Filosofía y letras, y que dice así: «¿Es la teoría literaria un estudio filosófico y, propiamente, fenomenológico?» ${ }^{2}$ Sobre esta cuestión planteada por Alfonso Reyes, el propio García Bacca se opone diametralmente a la idea de asociar teoría literaria -y su tipo de verdad-, a la teoría filosófica y la fenomenología.

Para el filósofo español, el concepto de fenomenología queda asociado necesariamente a la obra de Husserl. ${ }^{3}$ Por esa razón, García Bacca recrimina a Alfonso Reyes que el uso del término fenomenología, únicamente debe ser empleado tal y como Husserl lo desarrolla en dicha obra, es decir: como el estudio de las estructuras de la conciencia que capacitan al conocimiento para referirse a los objetos fuera de si misma.

De otro modo, cualquier uso del termino fenomenología contrario al canónico desarrollado por Husserl, no hará justicia a su sentido original. Atendamos a las razones por las que no es posible hacer fenomenología literaria según la opinión del propio García Bacca: «Mi tesis: que el fenómeno literario no es una fenomenología del ente fluido, sino una fluidificación de ciertos entes, una fluidificación de su verdad absoluta, eterna, inmutable, dándole forma de verdad sospechosa». ${ }^{4}$

Es decir, para García Bacca existe una distancia insalvable entre las formas de expresión literaria -metáforas- que constituyen su valor de verdad, y las expresiones filosóficas y ontológicas. Hoy diríamos: literatura y filosofía son dos órdenes de discurso distintos.

Las metáforas no pueden ser estudiadas bajo el método fenomenológico según García Bacca por una simple razón: «No es de estilo ni orden propiamente filosófico, pues no se asienta sobre nada ontológica o fenomenológicamente controlable; siempre, repito, que por fenomenología se entienda un método para resultados filosóficos sobre el ser o sobre el ser en cuanto objeto». ${ }^{5}$

1 A. Reyes 1944, pp.121-132.

2 J. D. García Bacca 1944, p. 17.

3 Nos referimos, como no, a $C f$. E. Husserl 1900-1901.

4 J. D. García Bacca loc. cit. 3, p. 123.

5 Ibid, p. 126. 
Es decir, la fenomenología propuesta por Husserl sirve -es en sí-, como un método específico para las actividades y temas propios de la filosofía -metafísica-. Si esto es así, entonces la fenomenología se ocupa de describir los fenómenos que acontecen en la conciencia y, a través de ellos, intentar exponer qué y cuáles - de un modo descriptivo-, son los principales fenómenos del ser del ente ${ }^{6}$-La pieza clave de todo el asunto reside, a juicio de García Bacca, en el tipo de verdad que atraviesa a la literatura y la poesía. Para el filósofo español, la verdad de la literatura y la poesía es la Verosimilitud: «Estrictamente hablando lo verosímil, en cuanto tipo de verdad original de lo poético, no es ni verdad ni semejante a la verdad [...]. Pero entre una metáfora y su tipo de verdad 'si es que insistimos en usar esta palabra' y la realidad y su tipo de verdad ontológica no hay semejanza alguna, ni a distancia finita ni a distancia infinita». ${ }^{7}$

Es decir, el orden de discurso respecto a la fenomenología no es el mismo y, por esa razón, no nos es posible hablar de fenomenología estrictamente hablando en literatura. No es posible, porque, a juicio de García Bacca, la fenomenología actúa sobre fenómenos reales de la propia conciencia. En el caso de la literatura, el filósofo español considera que la verdad es entendida como verosimilitud, es decir, como metáfora. Si esto es así, entonces no podemos hacer fenomenología de un ente no fluido, no vivo, no-real y puramente metafórico.

El filósofo español resume esta cuestión en tres argumentos:

1. «La verdad de tipo ontológico lleva siempre consigo una cierta imposición o deber ser: el de deber ser afirmada. En cambio: la verdad estética que vamos a llamar verosimilitud no nos impone semejante exigencia». ${ }^{8}$

2. «Es decir: lo literario presenta su contenido sin contenido, sin valor de verdad o falsedad. Y consiguientemente, verdad y falsedad, en el sentido filosófico de las palabras, nada tienen que hacer en estética y en literatura, y eso que en estos modos de expresión, al igual que en ontología o fenomenología, se emplea la palabra y hasta se da una cierta comunidad de estructuras verbales». ${ }^{9}$

3. «El método filosófico nada tiene que hacer con cosas que están hechas de manera que no tienen que ser ni verdaderas ni falsas, que no poseen, para decirlo con la fraseología clásica, el atributo trascendental de verdad». ${ }^{10}$

Para la forma de pensar de García Bacca en 1944, el paraíso de hadas que es la literatura y la poesía sirve, como mucho, de acicate positivo -ideal- y

6 En el caso de Heidegger, el proyecto fenomenológico heredado de su maestro Husserl intenta describir los fenómenos más inmediatos y familiares del Dasein incluyendo como novedad, el análisis de los estados de ánimo

7 J. D. García Bacca loc. cit. 3, p. 127.

8 Ibid, pp. 128-129.

9 Ibid, p. 128.

10 Ibid, p. 128. 
negativo - crítico- de las verdades, leyes y dogmas del mundo real del sujeto, es decir, del ente en el que, efectivamente, a diferencia de la literatura, la filosofía sí cabe la posibilidad de aplicar el método fenomenológico.

A nuestro juicio, lo interesante de todo el asunto y discusión es el cambio radical y profundo que sufrirá la tesis planteada por el propio García Bacca cuando, sólo un año más tarde -en 1945-, se publique una de sus obras más importantes. Nos referimos, sin lugar a dudas, a Introducción literaria a la filosofía. ${ }^{11}$

Esta obra es un buen ejemplo en dos actos de lo que, en el momento, pudiera ser considerado como un manifiesto intelectual reivindicando la importancia de la literatura y la poesía como forma de hacer filosofía en español. ${ }^{12}$

En la segunda parte de la obra de Introducción literaria a la filosofía, García Bacca intenta exponer el modelo filosófico español. Esta descripción crítica es crucial en un sentido muy concreto, a saber, compendia el sentido metafísico del filósofo español desarrollada a partir de la mitad de la década de los años 40 y toda la primera mitad de los años 50 del pasado siglo. Lo que nosotros proponemos es que, de algún modo, esta segunda parte de Introducción literaria a la filosofía, posee la suficiente consistencia argumentativa, como para darle el título de tercer pilar argumentativo de la década de los 40 y primera mitad de los $50 .^{13}$

\section{SENTIDO «DRAMÁTICO» DE LA FILOSOFÍA ESPAÑOLA:}

LA VIDA ES SUEÑO, EN TRES JORNADAS FILOSÓFICAS ${ }^{14}$

Jornada I.

La idea de García Bacca en esta primera jornada es clara y concisa, a saber, la de relacionar a Calderón de la Barca, ${ }^{15}$ con el enfoque filosófico -en el caso del personaje encarnado por Basilio-, como la filosofía de la ilustración:

11 Lo cierto es que esta obra fue originalmente publicada en el año 1945 bajo el título de Filosofia en metáfora y parábolas y reeditada en 1964. La edición que nosotros manejamos es: primera edición en Anthropos Editorial, 2003.

12 Manifiesto que evidencia los cambios de registro y de pensamiento del filósofo español. Por falta de espacio en nuestro trabajo, nosotros únicamente nos centraremos en la segunda parte de Introducción literaria a la filosofía dejando -de modo voluntario-, de lado la primera parte de la obra donde -sea referido de soslayo-, García Bacca realiza un paseo histórico y crítico por las diversas épocas filosóficas.

13 Los otros dos pilares sobre los que se sostiene la gestación de la propuesta metafísica garcibaccquiana durante la década de los años 40 del pasado siglo están constituidos por: Introducción al filosofar e Invitación al filosofar .

14 Para el presente epígrafe, seguiremos el método garcibaccquiano empleado en Introducción literaria a la filosofía, es decir, a través de distintas «Jornadas».

15 García Bacca apoyará su segunda parte de Introducción literaria a la filosofia, haciendo 
El hombre, al notar que por el cálculo podía predecir el futuro, hacer natural y no milagroso el oficio de profeta, se sintió semidiós. [...] Pues bien: cuando por las matemáticas en física, se pudo predecir el futuro y calcular parecidamente cuándo pasaron las cosas que no se vieron pasar, sucedió que el hombre pudo tener de vez, en presencia del espíritu matemático, lo pasado y lo futuro en el presente. Con la física matemática se dio a la ciencia un aspecto de eternidad, de victoria sobre el tiempo real. ${ }^{16}$

Es decir, la tesis de que el nuevo enfoque filosófico racionalista-científico defiende la idea de que se puede salvar el tiempo futuro entendido como porvenir, ${ }^{17}$ o lo que es lo mismo, como un tiempo que, a diferencia de Heidegger-como real/presente-, mantiene viva la idea de un tiempo futuro como no realizado y no calculable, es decir, abierto a las posibilidades.

García Bacca rechaza críticamente la postura de una filosofía enclaustrada en las supuestas virtudes de un futuro sin porvenir. Una filosofía donde el pensamiento filosófico-científico ha logrado reconvertir el porvenir en un tiempo futurible, es decir, un tiempo donde todas las posibilidades están previamente calculadas.

Un tiempo así entendido desde el enfoque existencial y futurible deja, en opinión del filósofo español, muy poco espacio para la sorpresa y el porvenir como fuente inagotable de posibilidades no pensadas, o lo que es lo mismo, no calculadas.

Todo el idealismo moderno, Kant inclusive, se creerá con derechos a fijar las condiciones de posibilidad de la experiencia por un examen a priori de las facultades interiores del hombre; y, con sospechosa coincidencia, convendrán todos en que el tiempo es forma pura, a priori; querrán ganarle las gracias al tiempo, y lo que conseguirá el Hombre [real], el de carne y hueso, el viviente, será [ser esclavo]. ${ }^{18}$

\section{Jornada II.}

A través del desarrollo paralelo de la obra de Calderón de la Barca ${ }^{19}$ García Bacca presenta el que, a su juicio, es el modo de filosofar español que, a diferen-

uso de la obra de P. Calderón de la Barca, La vida es sueño. Nosotros haremos uso de: Libro en la Red. Edición Electrónica: Diputación de Albacete - Servicio de Publicaciones - Gabinete Técnico www.dipualba.es/publicaciones. 2001.

16 J. D. García Bacca 2003, p. 253

17 La noción de «porvenir» que aquí aparece por primera vez en la obra de García Bacca, será de absoluta y determinante importancia en el futuro desarrollo de la obra garcibaccquiana.

18 Ibid, p. 261.

$19 C f$, P. Calderón de la Barca, La vida es sueño. 
cia de la filosofía metodológica y ensayística a la que nos tiene acostumbrados países como Alemania y Francia, España opta por desarrollar de forma literaria.

Lo destacable de esta segunda jornada es, a nuestro juicio, la aparición de la figura calderoniana del Hombre-Fiera empleada por el filósofo español en diversos sentidos. El primero, como radical oposición a la figura arquetípica de Hombre racional propia de la ilustración que tan duramente está criticando en este ensayo. En segundo lugar, como paradigma de lo que Ortega bautizó como razón vital, y de la que tanto uso hizo García Bacca durante los años 1939 y 1940.

El personaje de Segismundo en la Vida es sueño es, en esta segunda jornada, un hombre-fiera. Es decir, un hombre rabioso de su estar dormido y despistado, mareado por el incesante esfuerzo de Basilio por hacerle abrazar la verdad del despertar real. Un despertar de segundo grado logrado a través del proyecto racionalista. García Bacca concentra perfectamente la tesis de esta segunda jornada en estas escuetas líneas:

Que ahí está el punto del delito de todo racionalismo y ciencia media: [que nos quita el ser del hombre], e impele a los que hombres y padres se dicen y titulan pomposamente, con títulos en superlativo, a quitarnos el ser del hombre para así amansar la magnífica fiera vital, la altiva libertad. ${ }^{20}$

Es decir, el personaje calderoniano de Basilio es, a juicio de García Bacca, el representante perfecto de ese querer quitar al hombre de verdad -hombrefiera- el impulso humanizante de aquél que no desea someterse él mismo a planes futuros carentes de porvenir. García Bacca está apuntando, de ese modo, hacia la idea de un hombre y proyecto filosófico que nos recuerda, sin lugar a dudas, al plan y proyecto orteguiano que esconde su razón vital. Dice el filósofo español al respeto: «Y la razón [vital] de Segismundo le dictó una sentencia que debería avergonzar a reyes, pontífices, autoridades, educadores, padres, legisladores y Basilios todos que andan en autoridad por este mundo: Pues aunque el dar la acción es, más noble y más singular, es mayor bajeza el dar, para quitarlo después»». ${ }^{21}$

Según García Bacca, el propio Calderón hace la función de altavoz $^{22} \mathrm{del}$ sentir espiritual-moral del pueblo español. Si esto es así, entonces Calderón

20 J. D. García Bacca, loc. cit. 17, pp. 280-281.

21 Ibid, p. 281.

22 El término altavoz constituye un término clave en el desarrollo ontológico de García Bacca que merece cierta atención por nuestra parte. Atendiendo a la fórmula griega, advertimos que debido a su «estructura vital», decía en voz alta lo que silenciosamente eran las cosas. Aquí será donde García Bacca empleará por primera vez la expresión altavoz para caracterizar el sentido ontológico de la actividad metafísica del hombre antiguo. Para García Bacca, ser griego es ser 
estaría expresando en su obra teatral, el sentir popular de todo un país a propósito de las disposiciones filosóficas propias del racionalismo e ilustración más radical. Para ello, García Bacca destaca cuatro conceptos cruciales en la obra de Calderón que tienen, a su parecer, un sentido profundamente filosófico en el sentir del pueblo español.

1. «Alma. Tener alma quiere decir en lenguaje popular tener ánimos, ser animoso, emprendedor, decidido, tener alientos»». ${ }^{23}$ Es decir: el alma como ánimo y embate. A propósito de este temple especialmente animoso, el hombre popular entiende que los ánimos son la raíz de la Libertad radicalmente atrevida.

2. «Instinto. Conocimiento que el pueblo ha dejado e impreso en el individuo para mantener el alma y esencias populares contra las inexperiencias y veleidades del individuo, y a la vez iluminarle con la luz propia del alma específica del pueblo en sus acciones y reacciones, a fin de que sean castizas». ${ }^{24} \mathrm{Se}$ entiende que este instinto es otra raíz de la libertad que, al igual que ocurre con el alma, el instinto popular se inclina por lo atrevido a la hora de encaminarse a la libertad.

3. «Albedrío. Real talante, generosidad real, de soberano de sí y de las cosas, que se salta las leyes y razones, si es preciso, no por el simple afán de pisotearlas, sino por el más sublime de mostrarse Rey, Soberano, Dueño y Señor. $<$ Albedrío $>$ es arbitrariedad real, Privilegio y excepción de Gran Señor $>$. Albedrío es libertad con magnificencia». ${ }^{25}$ Es decir, el albedrío -entendido popularmente-, nos remite al hecho de hacerse uno cargo de sí y desde sí. Es muy frecuente en García Bacca, encontrar referencias al acontecimiento deseado y deseoso de ser uno Dueño y Señor de sí. Ser dueño de sí es condición esencial para entender el sentido de la libertad.

4. «Vida. Vida es poder de trasformación». ${ }^{26}$ La vida es, para García Bacca, siempre espacio de posibilidad trasformadora. Espacio existencial de autosuperación y cambio. En otras palabras: espacio fáctico para que la conciencia realice la experiencia de la libertad. Según concluye García Bacca de estos principios que rodean la obra teatral de Calderón -a propósito de las

altavoz del universo. Para el griego en su función de altavoz: palabras e ideas nacen del mismo sitio. Como altavoz, éste está conectado con el «cosmos». El antiguo griego con su lenguaje en función ontológica, puede «decir» lo que las cosas son, y lo que éstas le tienen que decir a él. García Bacca asegura que únicamente cuando el antiguo griego empieza a sentirse desconectado de las cosas, es cuando empieza a dejar de ser altavoz. Es decir, es cuando la pregunta ¿Qué es? Hace acto de presencia.

23 Ibíd, p. 287.

24 Ibid, p. 287.

25 Ibid, p. 288.

26 Ibid, p. 288. 
palabras de Segismundo en la tercera jornada-: la libertad tiene una relación intrínseca con lo ético, más que con lo puramente racional.

Segismundo sabe que, estando o no en un sueño, tiene que y debe liberarse del yugo impuesto por Basilio - principio racional-. Segismundo se revela, pues, como la alternativa española a los principios ilustrados. Segismundo es, en opinión del filósofo español, el paradigma de una libertad enraizada en conceptos tales como: alma, instinto, albedrío y vida. La libertad, así entendida, es una libertad ética, esto es: del deber hacer caso al envite existencial y atrevido de tener que hacer lo correcto.

Si esto es así, entonces la libertad se define como un tener que serse uno consigo mismo, es decir, hacerse cargo del envite radical humano de esa libertad que late y se impone como real gana.

Por el procedimiento calderoniano [la duda metódica teatral, el plan de Basilio], se descubre que nuestra realidad no sólo es, como realidad, más persistente que todos los objetos, pues desaparecidos o puestos todos en la disyuntiva [sueño o realidad], ella permanece firme en sí, sino que nuestra realidad, aun a cero de cosas, es firme en sí de hecho y de derecho, por obra del deber ser, del deber obrar bien, con cuya exigencia se afirma más en sí mismo, y puede luchar y prescindir de la cuestión metafísica y gnoseológica de si la realidad exterior es sueño o realidad. [...] Realismo ético es la solución española de la cuestión teórica sobre realismo e idealismo. [Hacer el bien y hacerlo para su pueblo y llevado por él]. Fracasan definitivamente todos los experimentos con que la Razón embaucó y venció a Segismundo la primera vez. ${ }^{27}$

\section{Sentido «auto-Sacramental» de la filosofía española. Plan on- TOLÓGICO, CÓSMICO Y SIMBÓLICO DEL MUNDO FÍSICO.}

La idea esencial de la primera parte de este extenso capítulo de Introducción literaria a la filosofía, titulado 1. Plan ontológico, cósmico y simbólico del mundo, puede resumirse en dos ideas esenciales. La primera de ellas -como idea central y general del capítulo-, es que García Bacca ha empleado un aspecto de la obra de Calderón de la Barca -La vida es sueño-, esencialmente como un modelo de auto sacramental desde un punto de vista secularizado.

Para García Bacca, es interesante tomar y trascender la noción de auto sacramental. ${ }^{28}$ Es decir, como -sobrenaturalizarse, sobreponerse-, en la medida

27 Ibid, p. 293

28 Hagamos uso de la explicación que de los autos sacramentales hacen I. Arellano, y J. E. Duarte en su obra El auto sacramental. 2003. Del siguiente modo definen el auto sacramental: «La representación que se hace de argumento sagrado, en la fiesta del Corpus Christi y otras fiestas» p.13; o como unas páginas más adelante, completan diciendo: «el asunto es siempre el 
en que, de estar en lo cierto, este esquema de autoelevación existencial sería el modo propio, característico y diferenciador del pensamiento filosófico español. La diferencia con el resto de modelos filosóficos es que, en el pensamiento español, al cómo del auto sacramental -sea o no entendido de modo religioso y cristiano-, se le incluye el quién como sujeto, es decir, como hombre de carne y hueso que desde sí, y arrojado en el mundo, debe elevarse hasta el punto de sobreponerse al universo como generalidad informe de cosas.

El hombre vive en el Mundo sobrenaturalizándose, sobreponiéndose constantemente. Ese proceso de auto sacramental que incluye al hombre constituye un proceso de elevación que engarza con la idea garcibaccquiana de trocar el Universo en Mundo. ${ }^{29}$ Pero, también, con una serie de pasos:

1. Orden ontológico: realidad neutra, física, matemática del universo.

2. Orden estético: en el que el mundo está regido por una necesidad de estilo.

3. Orden simbólico: donde el amor otorga el valor de sorpresa espontánea, es decir, un sentido superior al ontológico y estético.

Independiente de que el dador de ese orden y valor simbólico se otorgue en el auto sacramental a la Sabiduría y presencia divina, en el caso concreto de García Bacca, ese dador simbólico es el Hombre que, presente en un universo trocado en mundo, se sobrepone a sí y desde sí mismo haciendo que las cosas se presenten, en muchos casos, como algo sorprendente, inexplicable, inconcebible. García Bacca sentencia así esta importante tesis:

Y el que toda teoría sobre el origen de la vida en nuestra tierra y sus elementos [aire, agua...] no tenga carácter deductivo, necesario, sino que exija una mayor o menor provisión de inventiva en los sabios, nos indica que la Vida es, más que una necesidad ontológica o esencial, un imprevisible regalo, inesperado don, indeductible sorpresa. ${ }^{30}$

Como interesante conclusión, podríamos extraer la siguiente idea: para García Bacca, el filosofar español fundamenta su original carácter, en la idea de un proceso de autoelevación en un sentido muy concreto. Sentido que nada tiene que ver con la elevación o perfeccionamiento humano propia de una sobre explotación racional. La auto elevación propuesta primero por Calderón

mismo en todos los autos, mientras que los argumentos son diferentes (...) es verdad que trata siempre, en mayor o menor medida, del Sacramento de la Eucaristía, pero la variedad innumerable (sobre todo en el caso de Calderón), de los argumentos e ilustraciones de motivos en torno al gran tema de la Redención-Eucaristía, permite a su vez una gran variedad de formulaciones dramáticas concretas» (pp. 17-18).

29 La idea de trocar el Universo en Mundo es una de las principales tesis metafísicas garcibaccquianas. Para mayores referencias respecto a este asunto, consultar $C f$. J. D. García Bacca, Metafisica, 1963.

30 J. D. García Bacca, loc. cit. 17, p. 305. 
y, posteriormente, por García Bacca, tiene como referencia ontológica el auto sacramental que, como resultado, nos presenta el hecho ontológico del sobreponerse. En este sentido, el sobreponerse tiene que ver con la apercepción del sentido simbólico del universo trocado en mundo.

\section{EstAdos NATURAL, SOBRENATURAL Y SACRAMENTAL DE LA NATURALEZA HUMANA. EL MODELO SACRAMENTAL DEL FILOSOFAR ESPAÑOL}

Llegados a este punto de la argumentación garcibaccquiana, nos centramos en las últimas 10 páginas de Introducción literaria a la filosofía en las que el autor español nos dibuja, con mayor claridad y rotundidad, qué y cómo es, a su juicio, el filosofar característico del español.

Como sabemos, este filosofar original y particular español se ha realizado históricamente de modo literario. Por esa razón, García Bacca ha tomado la obra de Calderón de la Barca empleándola como altavoz del pueblo español. ${ }^{31}$

Lo primero que debemos destacar, pues, es la idea de que cada pueblo tiene una forma de filosofar. A juicio de García Bacca, no existe ni es posible hablar de algo así como una filosofía occidental o europeo a grandes rasgos. Mas bien, cada país y cada pueblo poseen, a su modo de ver, su propio modelo de filosofía y filosofar.

La realidad que llamamos nominalmente [vida humana], humanidad, está realmente especificada y diferenciada, dividida y aclimatada en diversas casi especies que se denominan Pueblos. Y de los Pueblos nacen las Naciones, y de las Naciones surgen, por procesos que aquí no interesan, esas formas siempre más o menos rígidas y técnicamente, más que vitalmente, organizadas que son los Estados. ${ }^{32}$

Lo primero que destacamos del argumento garcibaccquiano es aquello de: «realidad que llamamos nominalmente vida humana». La realidad como vida del hombre es, según lo entiende García Bacca, algo consustancial a la figura del Pueblo. Si lo real como humanidad es algo social, todos los enfoques filosóficos y, por lo tanto, metafísicos, éticos, morales, etc., encuentran su base y fundamento en los pueblos. Podría decirse, pues, que la ética - plano filosófico que aquí ocupa la atención de García Bacca- es, como podremos comprobar, un proceso permanente de autoinvención y reencarnación. Es decir, renaciendo

31 El concepto de "pueblo" es absolutamente determinante para la comprensión del giro "socialista" realizado por el filósofo español en los años 60 del pasado siglo. Para mayor información sobre la importancia del concepto de pueblo y su estrecha relación con la obra de Antonio Machado, consultar Cf. J. D. García Bacca, Invitación a filosofar según espíritu y letra de Antonio Machado, 1967.

32 J. D. García Bacca, loc. cit. 17, p. 352. 
una y otra vez en la especie natural que es el pueblo a través de los individuos que la constituyen.

De un modo más sencillo: la ética no nace de una conciencia individual que descubre, como en el modelo kantiano, unos principios categóricos y universales. ${ }^{33}$ Mas bien, ocurre que lo ético encuentra y asienta sus raíces en lo popular, o lo que es lo mismo, en el flujo permanente de la vida social de cada pueblo. Y dice García Bacca:

La popularidad puede y debe ser fin propio y directo, pues la humanidad propia y directamente se especifica en Pueblos. La ventaja de centrar la Ética en los valores a realizar apoyándose en esencias populares, en manifestaciones de cultura popular, no culterana o técnica, consiste en que tal Ética es viviente con las dos únicas vidas reales que existen: la de la especie y la del individuo de la especie. ${ }^{34}$

La ética, a juicio de García Bacca, hunde sus raíces en lo popular. La ética no debe su origen a algo individual. Tampoco debe ser entendida desde el prisma de lo universal: «Por su raíz o raigambre popular, la Ética supera el egoísmo individualista, sin caer en un altruismo o filantropía universal que desliga, sutilmente, de todos los compromisos para con lo real humano». ${ }^{35}$

Para García Bacca, la inmensa mayoría de los sistemas éticos han desarrollado sus principios éticos basándose, directa o indirectamente, en la idea de que la ética está constituida por un conjunto de principios de orden o corte universal. Principios que, hipotéticamente, nacerían de un sujeto especial y consolidado en su idea de esencia. Los proyectos éticos occidentales se asientan sobre la idea - para García Bacca errada-, de que existe algo así como una esencia universal en todo hombre. Especialmente, García Bacca está pensando en la regla de oro kantiana: «Obra sólo según una máxima tal, que puedas querer al mismo tiempo que se torne en ley universal». ${ }^{36}$

El hecho de que para García Bacca el origen y principio de toda ética sea lo popular, no implica que todas y cada una de las éticas populares puedan desarrollar el principio garcibaccquiano de la Transustanciación. ${ }^{37}$ En el caso del

33 Nos referimos, concretamente, a los principios a priori desarrollados por Kant en su obra Cf. Crítica de la razón pura, 1997.

34 J. D. García Bacca, loc. cit. 17, p. 353.

35 Ibíd, p. 354.

36 E. Kant 2000. p. 97.

37 El concepto transustanciación lo recupera García Bacca de la escolástica y, en este punto, es menester aclarar algunos aspectos importantes. En primer lugar, García Bacca lo toma de la Suma teológica de Santo tomas: "Dios es acto infinito, por lo cual su acción se extiende a la naturaleza entera del ser. Así que puede hacer que toda la sustancia de un ente se convierta en toda la sustancia de otro". [Santo Tomas. Suma, $3^{\circ}$ parte, 75, art. IV.] Si bien García Bacca parte de esta concepción tomista de la transustanciación, también es necesario señalar que el filósofo 
pensamiento y filosofía española - como ahora podremos comprobar-, el haber degenerado hasta el punto de convertirse en una ética de la transustanciación requerirá, según qué circunstancias especiales que, en el caso de occidente, únicamente se han dado en España. Analicemos esta cuestión paso a pasos.

Es cierto que el racionalismo puede vencerse en español mediante una moral de tipo popular, a base de bienes del Pueblo y para el Pueblo, y asentada sobre la Libertad, sobre el poder ser o no ser, con todo tal Ética ni es el ápice de la tendencia filosófica plenaria del español, porque no permite una real, genuina, total, absoluta, [transustanciación]. ${ }^{38}$

O lo que es lo mismo: que la ética depende directamente de cada pueblo. Es decir, de sus hábitos y costumbres y, aun así, ésta no asegura que el desarrollo y despliegue de dicha ética sea transustancial. ¿Cómo llega, pues, el pueblo español a desarrollar una ética basada y asentada en el principio de la transustanciación? García Bacca tiene clara la respuesta a dicha cuestión:

Por este motivo el alma española, en sus afanes incontenibles de superación de sí misma, aun de su ser mismo y en cuanto ser, acogió la doctrina cristiana de la Encarnación o Apersonamiento del Verbo, de una Persona divina, en la naturaleza como tabla de salvación para sus anhelos de total trascendencia. Y Calderón, haciéndose eco teatral de ese anhelo popular, prescindirá del hombre y nombre concreto de Jesús de Nazaret y hablará de una unión hipostática entre el Hombre y una Persona divina. ${ }^{39}$

Es decir: para García Bacca, el origen del impulso transustancial de la ética popular española responde, de algún modo, a una demanda existencial-vital propia del español que, en su empeño por renacerse a sí mismo, abraza la idea de la encarnación y unión divina con el Verbo.

Según la tesis de García Bacca, lo que el español hace en el ámbito de la filosofía y de la ética es, a propósito de la obra teatral de Calderón, readaptar el esquema ontológico de la transustanciación y unión hipostática propia de la teología católica por un lado, y la demanda del ímpetu español por otro lado para, de ese modo, reescribirlo desde un punto de vista secularizado.

español tiene muy presente al Cardenal Cayetano [Tomás de Vío] que, en palabras del propio García Bacca: "el único comentarista genial de la Suma": [J. D. García Bacca, 2000)]. Pues bien, García Bacca toma el término escolástico de transustanciación de la obra de Santo Tomás, y lo termina de asumir y absorber para sí, a través de los textos y comentarios que el Cardenal Cayetano realiza a de la obra de Santo Tomás. Como podremos comprobar a lo largo de toda la obra de García Bacca, el término transustanciación irá mutando y transformándose inevitablemente.

38 J. D. García Bacca, loc. cit.17, p. 356.

39 Ibid, p. 358. 
De otro modo, lo que García Bacca está afirmando es que el español, como pueblo, siempre ha tenido un anhelo ético propio de su carácter como nación, es decir, el ímpetu de querer rehacerse y renacerse existencialmente. La transustanciación es la forma peculiar y propia -autóctona- española de entender, vivir y padecer la idea universal y neutra de la trascendencia. La trascendencia, en el español, tiene forma y nombre concreto, a saber: transustanciación que, dicho sea de paso, es un tipo de trascendencia mucho más radical y profunda que la mera trascendencia de según qué principios y valores supuestamente universales.

La transustanciación del español responde, a juicio de García Bacca, a un anhelo profundo de querer sobreponerse al ser, o lo que es lo mismo, de superar -de modo íntegro-, su propio ser reencarnándose así en otro que nace de sí mismo. García Bacca concluye su tesis del siguiente modo:

Podemos, por consiguiente, concluir que, si es propio de todo hombre ese componente que se ha llamado trascendencia, la trascendencia toma en el español la forma de transustanciación. Por la trascendencia común y corriente en las filosofías occidentales el hombre trasciende o se eleva sobre cada ser en particular, se trasciende por manera de universal, de punto de vista superior a los casos y cosas concretas; llamaremos intencional, no se transustancia o sobrenaturaliza real y verdaderamente la esencia y sustancia del hombre. Toda filosofía europea clásica ha supuesto desde siempre que el hombre está bien hecho en su esencia y sustancia, que, por esto, las esencias son inmutables; empero el español cree notar en sus entrañas ganas rarísimas de nacer a otra vida radicalmente diversa de la que por nacimiento humano posee, nacerse a vida sobrenatural, trascender la vida misma en su plenitud, y trascenderla por algún modo de ella. A esta segunda potencia de la Eucaristía, tal como lo explica el dogma cristiano. ${ }^{40}$

En definitiva: la idea esencial que podemos extraer a propósito de las propias palabras de García Bacca es, a nuestro juicio, doble. De un lado, la idea de que la trascendencia sería algo así como un genérico de la propia transustanciación. Por otra parte, que el pueblo español -por su ímpetu y anhelo característico y único-, tomó la inevitable determinación de adoptar el esquema católico de la transustanciación aplicándoselo sobre sí mismo de modo secularizado.

Si esto es así, puede extraerse la tesis de que el español inclina su tendencia hacia la metafísica secularizada, y no hacia una ontología tradicional por una simple razón, a saber: porque sentirse proyectado hacia un más allá de sí es cosa diferente a una propuesta ontológica clásica entendida como ausencia de 
porvenir y exposición del ser desde un punto de vista clásico. ${ }^{41}$ La ontología sería, como pensaba García Bacca, el estudio sobre el ser inmutable de todo ente.

El ser del ente español es, en opinión del filósofo español, la transustanciación. Es decir, una especie de proceso dialéctico radical y permanente realizado por la propia conciencia sobre sí y desde sí. Este carácter especial del filosofar español es, tal y como nosotros lo vemos, el medio a través del cual, el filósofo español -al menos al inicio de su propuesta metafísica-, critica los principales proyecto ontológicos tradicionales y, al tiempo, reclamar un estatus filosófico propiamente español. ${ }^{42}$

Dice Izuzquiza en un momento dado sobre el filosofar en y por el español a propósito de García Bacca:

La lección para la filosofía es clara: no solamente ontología, sino ontología [aliñada] con estética. Una filosofía [en] castellano debe tener muy en cuenta la invalidez de una reflexión secamente ontológica, que no tiene un especial sentido para le modo de vida español. Es necesario considerar la ontología desde la estética, integrar la estética a un nivel de reflexión filosófica seria. Adviértase que esta consideración de la estética tiene mucho que ver con el sentido de totalización que toma la moral en el modo de vida español. La moral, como la libertad, no es vivida de un modo abstracto, sino que toma formas totales, plenamente integradas en la experiencia total de un pueblo; y solamente si se entiende esta totalización puede comprenderse que los problemas éticos adquieran carácter popular y no meramente académico. ${ }^{43}$

Cerramos el análisis de esta obra, con una referencia crítica por parte de García Bacca al proyecto heideggeriano, ${ }^{44}$ y que parece constituir en sí mismo,

41 No cabe la menor duda de que tanto nosotros, como García Bacca, nos estamos refiriendo con ontología y proyecto ontológico, a las desarrolladas por los Clásicos Griegos, en especial Platón y Aristóteles. El hecho de que García Bacca tenga una formación inicialmente escolasticista, determina la interpretación que el filósofo español tiene de los proyectos ontológicos que, sin duda, entiende como una búsqueda del Ser entendido como unidad, o primer motor inmóvil, como esencia fija, estable y universal. Para mayor información sobre la perspectiva clásica de la ontología en García Bacca, consultar Cf. De rebus metaphysice perfectis, seu de natura et supposito secundum primum totius philosophiae principium [Tesis Doctoral de Teología], 1930.

42 Lo cierto es que el tema de una filosofía o una forma propia del filosofar español desde la perspectiva garcibaccquiana es extensa y ampliamente trabajada por I. Izuzquiza en su obra: El proyecto filosófico de Juan David García Bacca, 1984. Especialmente en el capítulo III de la obra citada, y que lleva por título: «Filosofar en castellano: la originalidad del estilo de García Bacca» pp. 79-136. En este capítulo, Izuzquiza realiza un repaso y análisis sobre las principales características del sentido y necesidad de filosofar en español para el propio García Bacca.

43 I. Izuzquiza 1984, p. 95.

44 El peso e influencia de la propuesta metafísica heideggeriana en la obra de García Bacca 
una especie de alegato de defensa del carácter y naturaleza propia de filosofar en español que el propio García Bacca vindica para sí y para el pueblo español:

Qué es la vida? Un frenesí. Frenesí, no ímpetu vital, comedido o cohetero; ni menos moralidad con imperativos categóricos, disfraces delicados de imperios naturales; nada de Yo trascendente o vida fenomenológica pura, que todo ello presupone, como bajo de orquesta, la timbalera y monótona afirmación de que el hombre posee una esencia inmutable necesaria, eterna, diamante que desenterrar de entre las escorias de la vida empírica o sensible. Afuera todo eso de existencia auténtica, de Dasein heideggeriano, cuyo supuesto implícito es que dentro del hombre cotidiano hay un hombre de realidad de verdad que por sola modalización puede surgir del otro, sin cambios radicales, sin transustanciaciones. ${ }^{45}$

De este modo, García Bacca desestima para sí, cualquier indicio de algo así como una real y verdadera sustancialidad del hombre que, a modo de diamante, constituya el núcleo esencial y duro de lo que el hombre es en sí mismo. Para García Bacca, el proyecto heideggeriano falla en el supuesto de que, partiendo únicamente de un proceso fenomenológico que describa su mundanidad, el hombre sea capaz de extraer la auténtica y real presencia o esencia del ser del ente.

Nosotros nos preguntamos si en el caso del proyecto metafísico de García Bacca, ¿no existe algo así como una relativa sustancialidad del hombre a propósito de un ímpetu tan peculiar como el de la transustanciación?

\section{CONCLUSIÓN}

En el presente artículo nos hemos centrado en la importancia que para García Bacca tiene el modo de filosofar español, así como la gestación de una tesis propia respecto a las posibilidades mismas de la literatura como principio esencial del filosofar español. Hemos descrito las propias discusiones en torno a la posibilidad del ejercicio filosófico desde la literatura, así como la naturaleza de verdad o verosimilitud de la filosofía y la literatura respectivamente.

Creemos haber podido mostrar y demostrar cómo existe un cambio profundo en la forma de pensar garcibaccquiano respecto a las posibilidades de la ontología. Si bien el tono filosófico de García Bacca es de marcado tono

es clave para la comprensión del desarrollo de la propuesta metafísica garcibaccquiana propia de los años 40 y 50 del pasado siglo. Pero, también importante para comprender en su justa medida el tránsito desde la etapa existencialista garcibaccquiana, hacia otros puntos de vista más próximos al socialismo y el marxismo desarrollados por el filósofo español especialmente a partir de los años 60 del pasado siglo. Para mayor información sobre el papel de la obra heideggeriana en el filósofo español, consultar $C f$. J. D. García Bacca, Existencialismo, 1962.

45, J. D. García Bacca, loc. cit. 17, p. 360. 
escolasticista y lógico desde el inicio de sus escritos allá por 1930 hasta 1944, creemos haber podido demostrar que, a partir de 1945, existe un cambio profundo de paradigma respecto a la forma de pensar las posibilidades ontológicas de la literatura y la poesía como fuente de reflexión filosófica. Este cambio de paradigma filosófico se revela como absolutamente determinante pues, a partir de la década de los años 60, la propuesta metafísica garcibaccquiana varía hacia un tipo de materialismo socialista alejado de las versiones más elitistas de la filosofía. Su interés por la poesía de Antonio Machado, así como por el "pueblo" como foco central de sabiduría en el que debe centrarse toda la actividad crítica y reflexiva del filósofo no es casual.

Sin atender a las razones por nosotros expuestas en el presente artículo respecto al origen y sentido de dicho cambio de orientación filosófica, creemos que será prácticamente imposible comprender e interpretar correctamente las razones que empujaron a García Bacca a interesarse por la obra de Machado. Un interés por Machado que determina definitivamente el cambio de orientación filosófica garcibaccquiana desde el existencialismo característico de los años 40 y 50 del pasado siglo, a un tipo muy heterodoxo de socialismo y marxismo propio de los años 60,70 y 80 . De algún modo, el renovado interés por la filosofía en español -y el modo de hacer filosofía característicamente en prosa y verso- contribuyen, de manera inestimable, a que García Bacca ponga en práctica un nuevo paradigma ontológico que, hasta 1945, se basaba fundamentalmente en los modelos clásicos de la escolástica y la antigua Grecia.

García Bacca reconoce, pues, que existe algo así como un modo, carácter y manera propia de hacer filosofía en español. Un modo que históricamente se ha desarrollado de modo independiente a las grandes tradiciones y corrientes de la filosofía continental tradicional como Alemania o Francia. García Bacca creer reconocer un carácter auténtico y original en la forma no sólo de desarrollar el discurso filosófico del español. Cree, también, que el español -o la filosofía en español-, nace de una visión ontológica basada en la transustanciación secularizada que asienta las bases de una nueva forma de pensar más próxima a la dialéctica, que las corrientes ontológicas clásicas y, a juicio del filósofo español, inmovilistas.

Xauier Gimeno es doctor por la Universidad de Valencia.

\section{Lineas de Investigación:}

Filosofía contemporánea. 


\section{Publicaciones:}

«La crítica de Juan David García Bacca, a la categoría de Angustia heideggeriana» en Estudios fenomenológicos- Publicado.

«Sobre tres ejercicios literario-filosóficos de moral desde el prisma de Juan David García Bacca» en Daimon-Publicado-.

Correo electrónico: xagimon@hotmail.com 